مجلة جامعة الملك عبدالعنيز: الاقتصاد الإسلامي، م31 ع3، ص ص: 155-174 (محرم 1440/ أكتوبر 2018)

DOI: 10.4197 / Islec. 31-3.10

مراجعة علمية لكتاب:

"Le mensonge de la finance: Les mathématiques, le signal-prix et la planète » Nicolas Bouleau, Paris: Editions de l'Atelier, 2018.

\title{
"أكذوبة الأسواق المالية: الرياضيات والإشـارات السعرية ومصير الأرض من الناحية البيئية" لنيكولا بولو، باريس: منشورات لاتوليي، 2018م
}

\author{
مراجعة: عبدالرزاق سعيد بلعباس \\ أستاذ مشارك - بمعهد الاقتصاد الإسلامي

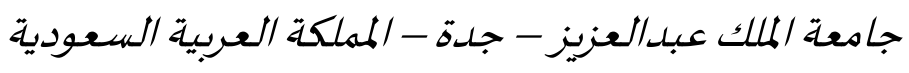

المستخلص: يطرح الكتاب سؤالاً جوهريًا عن حقيقة الإشـارات السعرية في الأسواق المالية العالمية

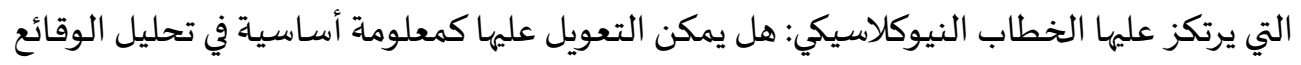

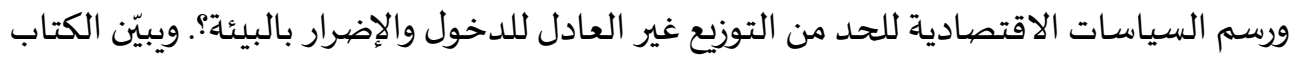

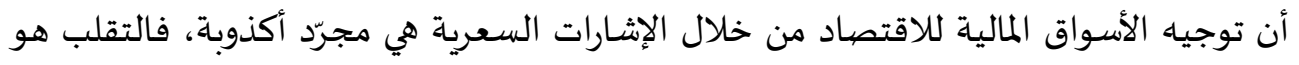

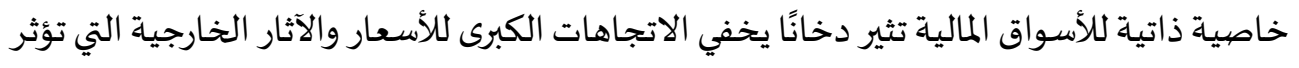

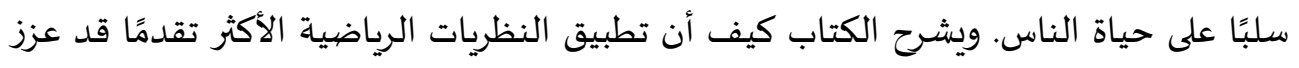

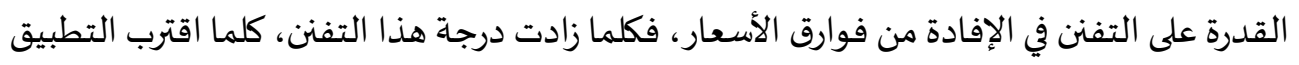

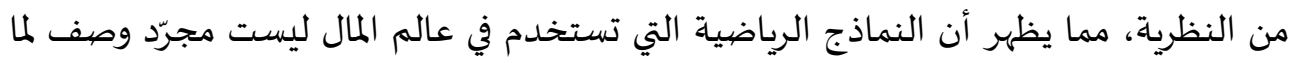

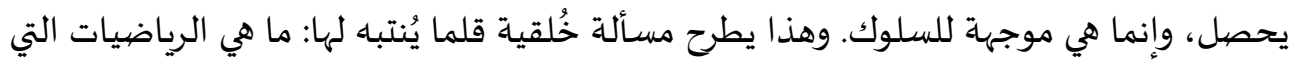

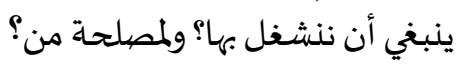

الكلمات الدالة: الأسـواق المالية، التقلبات، المجازفة، النظرية الرياضية للمفاضيلة، توجياء السلوك.

تصنيف B26, C02, D53, G14 :JEL

F51, H24 :KAUJIE 


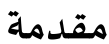

في محاضرة ألقاها في منتصف السبعينيات من القرن الماضي في جامعة فانسين أن اللّغة ليست مجرد وسيلة

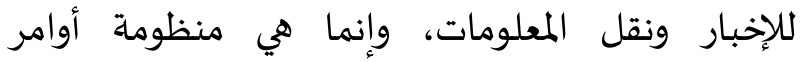

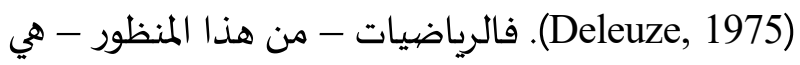
بمثاباة لغة باطنية (esoteric) مقصورة على فئة محدودة

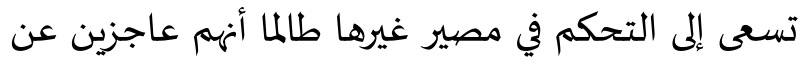
إدراك ما يدور حولهم أو أنهم اقتنعوا باستحالة إدراكه بعمق دون استخدام الرياضيات. وإذا كانت الأسـواق المالية تهمين على مسـار الاقتصياد المعاصر وتفرض قوانينها على الحكومات، فإن الرياضيات

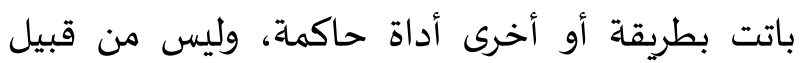
المصيادفة حصول روبرت مرتون وميرون سكولز (Merton) Scholes \& -عن المعادلات التي تستخدم في الأسواق المالية والتي أفرزت

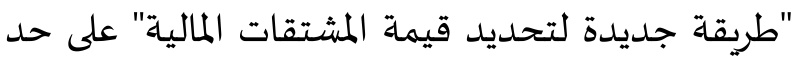
تعبير القائمين على الجائزة(2). فالدافع الأساسي لم يعد الرغبة في خدمة المجتمع، أو مواجهة التحدي لحل مسائل

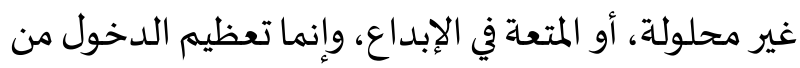
خلال خدمة مصالح المستفيدين الكبار من المجازفة في

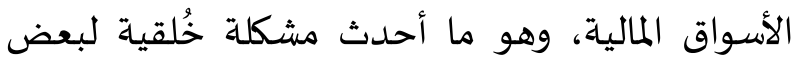

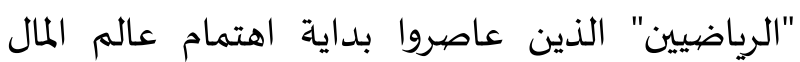
بالرياضيات المتقدمة على غرار مؤلف الكتاب كما سيتضح

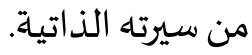

(2) The Sveriges Riksbank Prize in Economic Sciences in Memory of Alfred Nobel 1997, https://www.nobelprize.org/nobel_prizes/economicsciences/laureates/1997/

لم يحصل فيشر بلاك (Fischer Black) على الجائزة لأنه توفي في 30 ألجائ

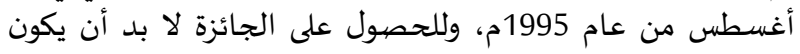
المرشح على قيد الحياة.
تكمن أهمية الكتاب الذي بين أيدينا من تأليف باحث محنك في الرياضيات في كشفه عن المحور الذي ارتكزت علياء النصوص المؤسسة(1) للخطاب النيوكلاسيكي منذ هاية الحرب العالمية الثانية إلى أبعد من الفروض الأسساسية التي ارتكز عليها النقاش حتى الآن في أوساط الاقتصاد الإسلامي، مما يجعل هذه الفروض شكلاً من أشكال

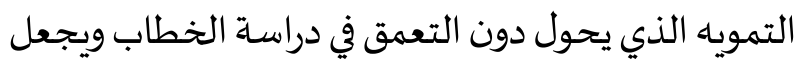
النقد محدودًا (بلعباس، 2011: 113). وركز المؤلف طيلة سنين طويلة على هذا المحور - الذي يتثمل في إشـارات الأسعار - للنظر في مدى مطابقته لواقع الأسواق هـاق المالية، ما تطلب الكثير من الجهد والصبر والمثابرة مع توخي الدقة والأمانة والموضوعية، وجعله لا يتعامل مع المفاهيم

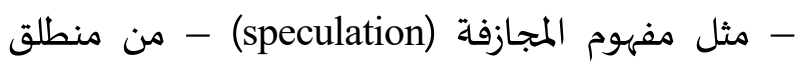

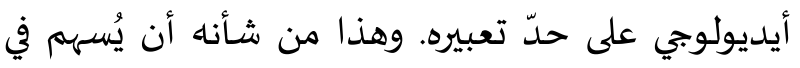
تعميق الفهم للظواهر كالتمييز بين أشكال مختلفة للمجازفة من جهاة، والتمييز بين المجازفة والمفاهيم ذات

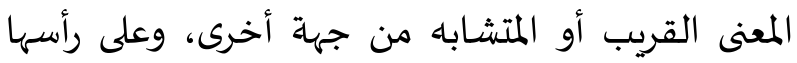
مفهوم المفاضلة (arbitrage) كما سيتبين لاحقًا. وعلينا ألا نغفل أن الوقائع يتم بناؤها من قبل الفرق البحثية وأنه ليس هناك فرق بين العناصر الاجتماعية

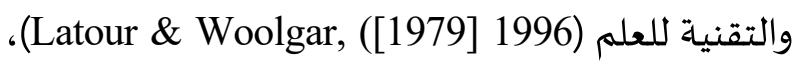
مما يجعل اعتبار الاقتصاد بأنه علم طبيعي لتمييزه عن العلوم الاجتماعية وصف يحتاج إلى إعادة نظر. كما علينا

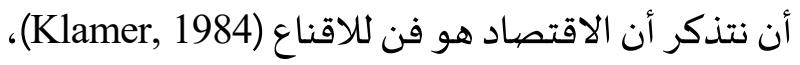

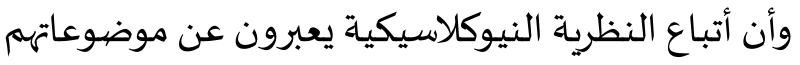
ضمن إطار يندرج في لغة التخصص التي تحدّد كيفية النظر إلى العالم، وقد أشار جيل دلوز (Gilles Deleuze) 
محدّد، بدلاً من إتاحة المجال للإبداع الحر والتحفيز على

$$
\text { تنويع طرق الفهم للوقائع والظواهر والسلوكيات (4). }
$$

انطلاقًا من قناعة أن خصوبة الأفكار تنبع من القراءة الخارجية، اهتم المؤلف بمجالات بحثية عديدة من أبرزها: الاحتمالات ونظرية الاحتمالات، وفلسفة النمذجاة، والهندسة المعمارية، والمخاطر المالية، واقتصاديات تغير المناخ والانتقال الذي يراعي المعايير البيئية، وتاريخ وفلسفة العلوم، وهو يدعو إلى الاستخدام الناقد للنمذجة الرياضية كما تدل الأسئلة التي بنى عليها كتابه "النمذجة

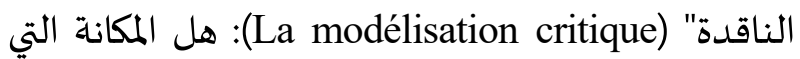
تحتلها اليوم النمذجة في العلوم والتقنيات اغتُصِبت لمصلحة فئة محددة؟ هل الرياضيات التي ترتكز عليها النماذج هي ضامنة لتمثيل مفيد ونافع للواقع؟ ما هي الاقتصادات التي تصمم لأجلها النماذج؟ ولأي قرارات تصلح؟ وهي أسئلة لا تخلو من مواقف وآراء جريئة قلما يطرحها "الرياضيون" (Bouleau, 2014)؛ فهو ليس باحثًا تقليديًا في الرياضيات، وإنما رياضي مفكر تفاعل - بما أتيح لله من فرص وإمكانات - مع قضايا مجتمعة والتحديات الكبرى التي تواجهها البشرية في الوقت الراهن، لكن علينا ألا نغفل أن تفكيره يبقى متأثرًا بالموروث الثقافي الذي اكتسبا وتربى عليه والسياق الاجتماعي الذي ترعرع

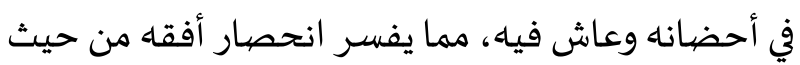
السياسة الاقتصادية بين الاعتبارين الاجتماعي والبيئي

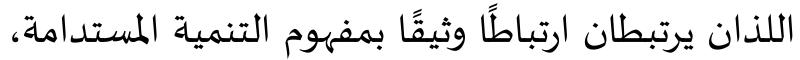

(4) أنظر على سبيل المثال الندوة العلمية التي نظمتها مدرسة الأساتذة العليا (Ecole Normale Supérieure) بباريس في 14 ديسمبر 2017م حول موضوع "الرياضيات بين المعيارية والخيال" ديال ،(Les mathématiques entre normativité et imagination) والتي شارك فيها مؤلف الكتاب الذي نراجعاه.

\section{1- نبذة مختصرة عن السيرة الذاتية المؤلف (3)} ولد المؤلف في باريس عام 1945م، وهو يبلغ من العمر ثلاثة وسبعون عامًا. بعد أن تخرج من مدرسة الفنون المتعددة (École Polytechnique) في فرع مدرسة مدرسة الجسور والطرق (Ponts et chaussées)، درس الهندسة المعمارية قبل أن يتوجاء نحو البحث العلمي في الرياضيات،

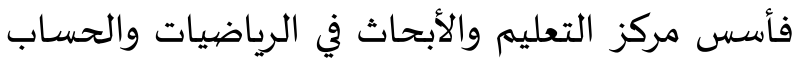
العلمي (CERMICS) في مدرسة الجسور والطرق، وهو أستاذ فخري (professeur émérite) أشرف على كرسي "الاحتمالات والعمليات العشوائية"، وتولى تدريس الرياضيات، وتارتخ العلوم والابستمولوجيا، وفلسفة العلوم، والابستمولوجيا وفلسفة العلوم، وله تسعة عشر كتابًا وواحد وسبعون بحثًا. والمفزى من تدريسـ لفلسفة العلوم هو بيان أن العلم لا ينحصر في تطبيق بعض الإجراءات الفنية على الظواهر الواقعية والمحسوسة لاستكشاف ما بينها من علاقات أو قوانين، وهو جوهر الخطاب الوضعي (Positivist). أما المبحث الرئيس للابستمولوجيا فيتمثل في الوقوف على طرق تمييز ما هو علمي من معرفة عما سواها، وفهم العمليات التي يمكن أن تؤدي إلى وصف شكل من أشكال

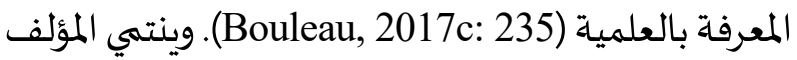
إلى مجموعة من الباحثين في الرياضيات الذين يستنكرون تريض (mathematisation) العالم، مما أدى تدريجيًا إلى النزعة الكمية والنظرة الاختزالية وتوجياء التفكير نحو نمط

(3) استخلصت هذه النبذة من سيرته الذاتية، ومقابلات متاحة على اليوتوب، ومقالة له بعنوان "وداعًا أيها التمويل" ( Adieu la Le blog de Nicolas ( متاحة على مدونتـه الشخصية ومهية (finance

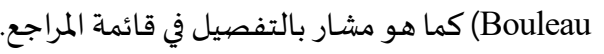


تحقيق الريح من دون مخاطرة، وهو تعريف مههم مهدف إلى إظهار أن هذا السلوك هو حالة استثناية تظهر بين الفينة والأخرى ولكنها سرعان ما تختفي. من الناحية التاريخياة، ظهرت المفاضلة في سوق العملات للمتاجرة بفروق الأسعار وتحقيق ربح من جراء ذلك كما يشير قاموس الأكاديمية الفرنسية لعام 1835م (Académie française, 1835, 1:96). والمهم في الأمر هو النظرية الرياضية للمفاضلة التي تُقَسِّمُ سعر الأصِول المدرجة في الأسـواق المالية إلى جزئين: ما يرتبط بالقمار ويتغير بطريقة متقطعة (martingale)، وما يسمح بقياس اتجاه أكثر انتظامًا على مدار فترة زمنية محددة (tendance). ويتضح بموجب هذه النظرية

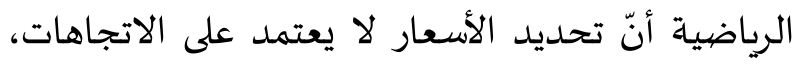

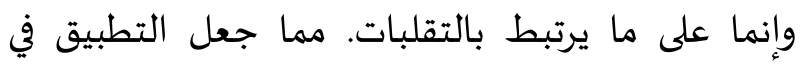
الأسواق المالية يقترب كثيرًا من النظرية الرياضية، وكلما زادت درجة التفنن للإفادة من فوارق الأسعار من جراء

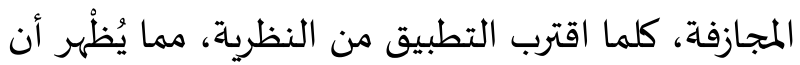
النماذج الرياضية التي تستخدم في عالم المال ليست مجرّد

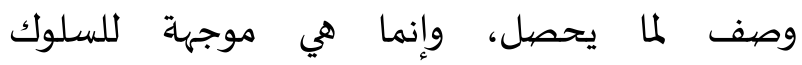
(Performative) محدّدة (fixed point) ينبغي الوصول إليها بأي طريقة. في بداية الثمانينات، بدأت البنوك الكبيرة توظّف خريجي مدارس الهندسة للإفادة من مهارتهم في الرياضيات المتقدمة التي باتت اليوم تضاهي تلك التي تستخدم في

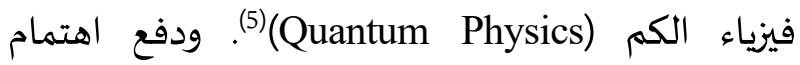
المصرفيين بهذا النوع من الرياضيات المتطورة المؤلف إلى التساؤل عن مغزى ذلك: هل هم جادين في ذلك أم هي مجرّد إرهاصات فكرية؟ فبدأ مع فريق مركزه البحثي في هي هي

(5) أشار المؤلف في مناسبات عدّة أن الرياضيات التي تستخدم في الاقتصاد بدائية مقارنة بتلك التي تستخدم لنمذانة المان الأسواق المالية.
وهو يعطي الأولوية للمشكلات التي تجابه البلدان الغنية ماديًا وفقًا للناتج المحلي الإجمالي. وكان المؤلف من أوائل المهتمين في أواخر سبعينيات Bouleau, ) القرن العشرين بالنمذجة الرياضية في التمويل (1998; 2009; 2013; 2017a; 2017b نظرية المفاضلة (Théorie de l'arbitrage)، وهو مفهوم محوري في التمويل ترتكز عليه نظريات عدّة في مقدمتها: النظرية المالية للشركات ) Modigliani \& Miller, 1958 1961)، ونظرية الخيارات (Black \& Scholes, 1973)، ومعاملات المتاجرة في العملات، ويمكن التمثيل لمبدأ المفاضلة في العلاقة الثلاثية التي يتم اللجوء إليها عادة في سوق المتاجرة بالعملات. لنفترض ثلاث عملات: اليورو

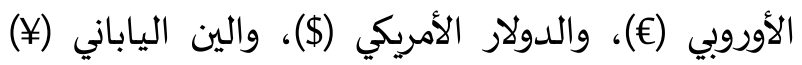
بقيمة التبادل التالية في شهر مايو 2018م: ولمون

$$
100 \text { دولار أمريكي = } 10.84 \text { ين = } 10.76 \text { دورلار أمريكي = يورو } 110.87 \text { ين }
$$

في هذه الحالة يشتري المجازفون دولارًا واحدًا بقيمة 0.84 يورو، ويبيعونه لشراء 110.87 ينًا، وبهذه "الينات"

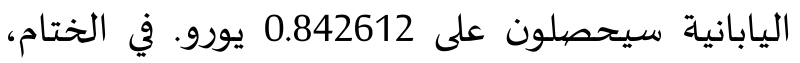
بقيمة .0.84 يورو، حصل المجازفون على 0.842612 يورو تقريبًا في نفس الفترة. فهناك فرصة مفاضلة تتمثل في ربح قيمته 0.002612 دون خطر، وكلما تضاعف حجم العملات المتبادلة، كلما كانت الأرباح أكبر بطبيعة الحال. فالمفاضلة (arbitrage) تعني من الناحية اللغوية المقارنة بين شيئين للموازنة بينهما والنظر أيهما أكثر أو أقل

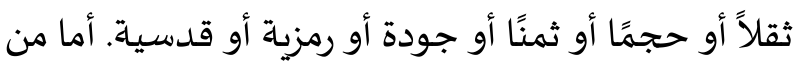
الناحية الاصطلاحية، فهي تعني في الأدبيات النيوكلاسيكية 
في عمل الأسواق المالية - هي بمثابة الدخان الذي يخفي

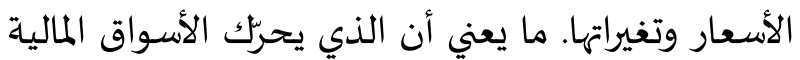

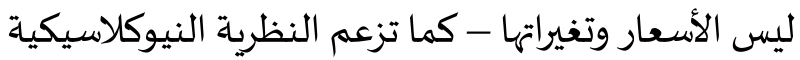

- - م، وإنما التقلبات الشديدة والحادة التي تحدث يوميًا.

2- المفاهيم الرياضية الأسساسية التي ترتكز عليها نمذجة

\section{الأسواق المالية}

بإمعان النظر في مادة الكتاب، يتضح أن نمذجة الأسواق المالية ترتكز على ثلاثة مفاهيم رياضية أساسية،

أولا: مفهوم المرنتغال (martingale) الذي ينحدر من

اللغة الفرنسية بناءً على كلمة يرجع استخدامها حسب المباء المصادر الموثوقة إلى عام 1491م، وهو يعني في لغة المقامرين "سر الفوز"، وكان يتمثل في الأصل في المقامرة بضعف ما تم خسارتا، ثم بات يعني بصفة عامة أيّ وايّ

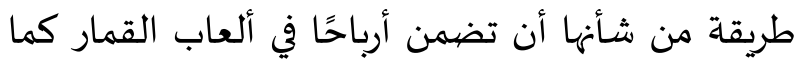
يشير قاموس الأكاديمية الفرنسية في طبعته التي صدرت في Académie Française, ( بداية القرن التاسع عشر .(1835, 2: 173

إذا أردنا أن نمثل للمرنتغال القائم على المراهنة بضعف

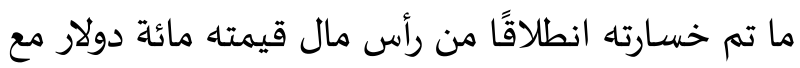
افتراض أربع خسارات متتالية وربح، فإننا نحصل على من مانى النتائج الملخصية في الجدول رقم (1) بناء على المعادلة

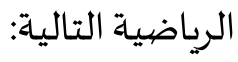
رأس المال المتبقي=رأس المال الأصلي + الرتح أو الخسارة المتراكمة
الرياضيات العمل في الموضوع بالتعاون مع بعض المصرفين الذين يُتَجارون في الأسواق المالية. وهنا حصل تقاطع بين

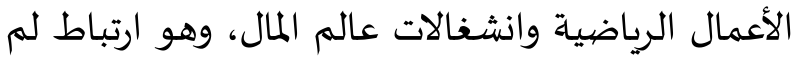
يتوقعه أحد، وقد ساهم تطور المجازفة إلى مطابقة الأسـواق المالية مع الرياضيات من خلال نظرية المفاضلة. هكذا بدأت مغامرة المؤلف الفكرية غير المتوقعة مع عالم المال، ولم يكن الأمر محفزًا من الناحية البحثية فحسب، وإنما كان نقطة تحول تاريخية في الرياضيات التطبيقية، مما انعكس على مسار البحث والتدريب المهني على حد سواء. وخلال هذه الفترة المبكرة من الرياضيات المالية، كانت القضايا الخُلقية تطرح بين الفينة والأخرى، لاسيما مخاطر توظيف البحث العلمي في الرياضيات لمصلحة ذوي النفوذ المالي وفي مقدمتهم المصارف الكبرى التي كانت تنشط في سوق مال باريس. وأشار المؤلف أن البحث العلمي كان أكثر حرية عندما كان يمول من الدولة

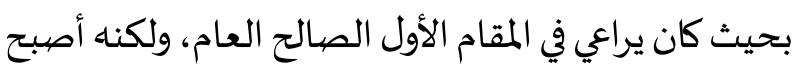
موجها إلى حد كبير عندما فتح المجال للقطاع الخاص الذي سخر الكفاءات العلمية التي صرفت عليها الدولة مبالغ باهظة إلى خدمة مصالح المصارف والمكاتب المالية الكبرى. هذا التحوّل جلب اهتمام بعض الباحثين في علم اجتماع المعرفة الذين كشفوا أن جل الباحثين في المراكز البحثية باتوا يخضعون لقوى اقتصادية ليسوا على وعي بها .(Stengers, 1996; Segerstrale, 2000) ويشير المؤلف في هذا الكتاب إلى ظاهرة كبرى من شأهها أن تغيّر نظرتنا للأسواق المالية بصفة جذرية، وهي أن التقلبات - التي ليست حادثة عابرة، وإنما سمة جوهرية 
جدول (1). مثال لمرنتغال مبني على خمس مراهنات

\begin{tabular}{|c|c|c|c|c|}
\hline رأس المال المتبقي & الربح أو الخسمارة & النتيجة & 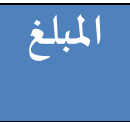 & مراهم \\
\hline 99 دولار & - 1 دولار & خسارة & ا 13 دولار & المراهنة (1) \\
\hline 97 دولار & - 3 دولار & خسارة & 2 دولار & المراهنة (2) \\
\hline 93 دولار & - 7 دولار & خسارة & 4 & المراهنة (3) \\
\hline 85 دولار & - 15 دولار & خسارة & 8 دولار & المراهنة (4) \\
\hline 101 دولار & - 1 دولار & رب & 16دولار & المراهنة (5) \\
\hline
\end{tabular}

المصددر: من إعداد المُراجع.

المزيد والمزيد من الحظ للفوز؛ وهو اعتقاد خاطئ لأن

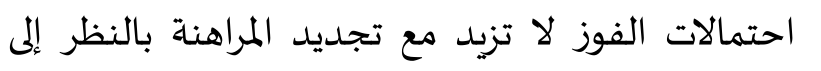

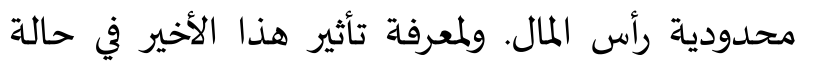

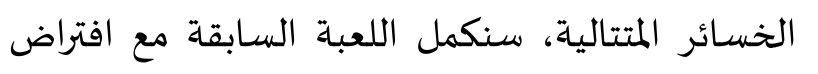
ستة خسائر متتالية كما يظهر في الجدول رقم (2).
هذا يوضح أن فرضية المرنتغال ترتكز على الفكرة التالية: "إن الحظ سوف يتحول لصالح المقامرين عاجلاً أم آجلاً"؛ وهو تصور خاطئ وخطير. فالمرمنتغال ممارسة خطيرة لأنها

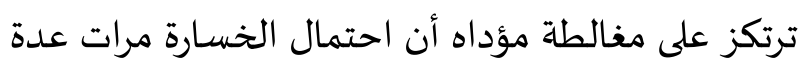

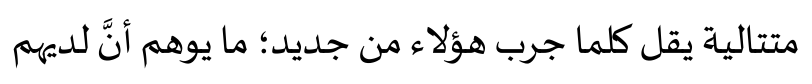
جدول (2). مثال لمرنتغال مبني على اثني عشر مراهنة

\begin{tabular}{|c|c|c|c|c|}
\hline رأس المال المتبقي & الربح أو الخسسارة & النتيجة & 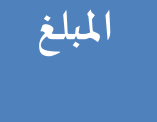 & رقم المراهنة \\
\hline 99 دولار & - 1 دولار & خسارة & 1 & المراهنة (1) \\
\hline 97 دولار & - 3 دولار & خسارة & 2 دولار & المراهنة (2) \\
\hline 93 دولار & - 7 دولار & خسارة & 4 دولار & المراهنة (3) \\
\hline 85 دولار & - 15 دولار & خسارة & 8 دولار & المراهنة (4) \\
\hline 101 دولار & ( 1 دولار & ربح & 16 16دولار & المراهنة (5) \\
\hline 100 & 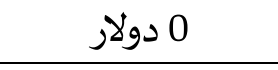 & خسارة & 1 & المراهنة (6) \\
\hline 98 دولار & - 2 دولار & خسارة & 2 دولار & المراهنة (7) \\
\hline 94 دولار & - 6 دولار & خسارة & 4 دولار & المراهنة (8) \\
\hline 90 دولار & - 14 دولار & خسارة & 8 دولار & المراهنة (9) \\
\hline ( 70 دولار & - 30 دولار & خسارة & 16دولار & المراهنة (10) \\
\hline 38 دولار & - 62 دولار & خسارة & 32 دولار & المراهنة (11) \\
\hline لم يبق ما يكفي للمراهنة & $\ldots$ & خسارة & 64 دولار & المراهنة (12) \\
\hline
\end{tabular}

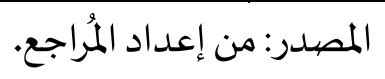




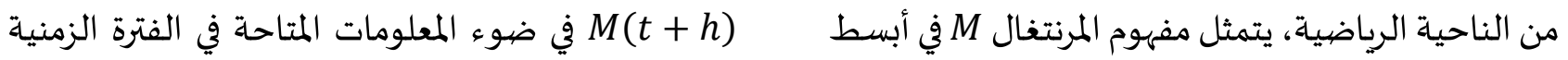

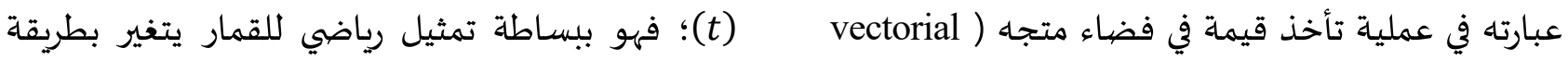
(space)، بحيث تمثل القيمة M(t) أفضل تقدير لٍِ : متقطعة كما يظهر في الشكل رقم (1). شكل (1). محاكاة منحنى مرتنغال في سوق المال

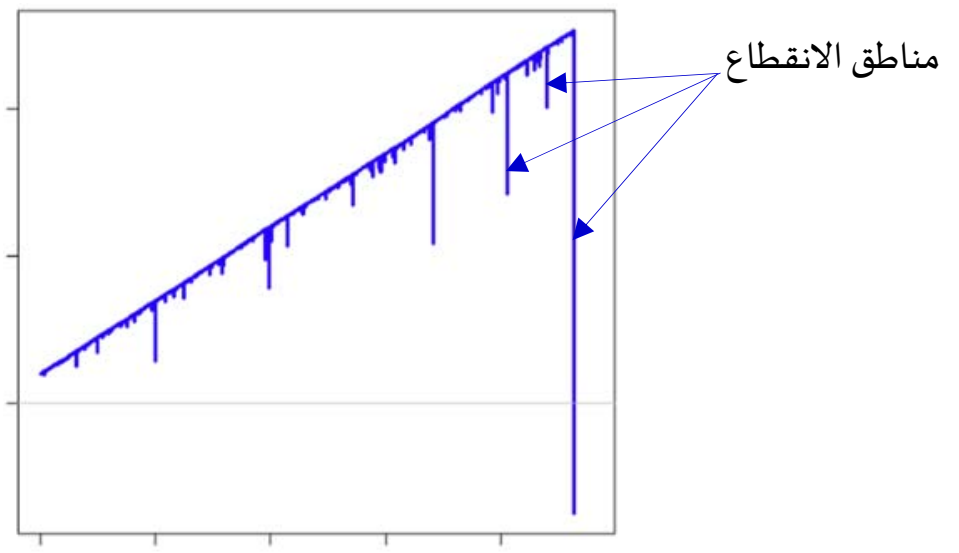

ثانيا: الظاهرة المتمثلة في الحركة العشوائية لجزيئات في 1858م). وعلى أساس هذه الحركة يمكن تحديد عدد مائع كما يظهر في الشكل رقم (2)، والتي توسم بحركة كبير من العمليات العشوائية الأخرى التي تفي بمبادئ براون (brownian motion) نسبة للباحث الأسكتلندي في الحساب التفاضلي (differential calculus). علم النباتات روبرت براون (1773) (Robert Brown) علمن

\section{شكل (2). حركة براون لجزيئة من نقطة البداية إلى النهاية}

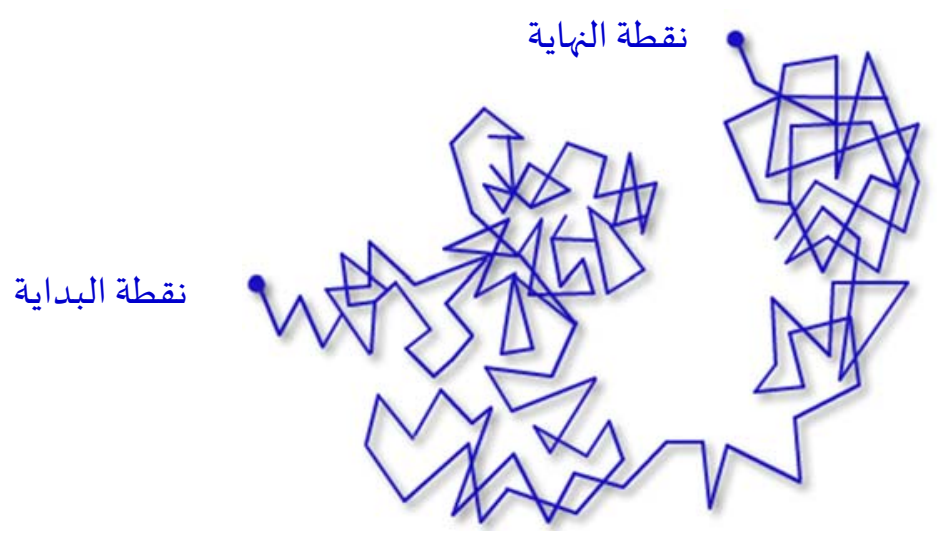

بالعقل، كما يختلف سلوكه في أنه معقد يتحكم في تكوينه

هذا يبين أن النمذجة الرياضية في الأسواق المالية صيغت قياسًا على الظواهر الطبيعية، وشتان بين الإنسان عوامل متعددة لا يسع المجال هنا للخوض في تفاصيلها. والكائنات الحية؛ فالإنسان يتميز عن بقية المخلوقات 
يشتري في الزمن (0) وحدة واحدة ويبيعها في الزمن (1)،

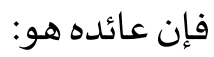

(process عنها - تطورًا للمتغير الاحتمالي. أهم ما يستخلص من هذه المفاهيم الأساسية أن الن النيا الرياضيات وظفت منذ سبعينيات القرن العشرين في عالم التمويل لنمذجة المجازفة ليصبح كل منهما يغذي الآخر، وهو تحول معرفي يحتاج إلى دراسة جادة بحيث أن العلم بات يوظف لخدمة مصلحة فئة معينة تمتلك المال والنفوذوعلى رأسها المصارف الكبرى.

فيما يلي خطة الكتاب وأبرز ما جاء فيه، وهو يتضمن

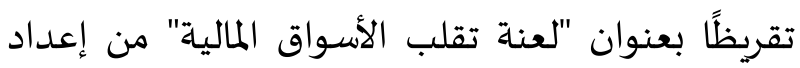

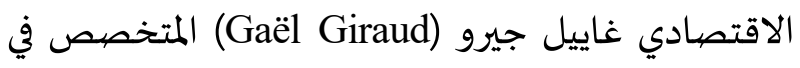
الاقتصاد الرياضي، ومقدمة للمؤلف، يتبعها خمسة الإنهادي

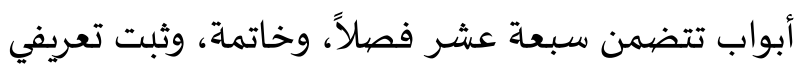
بأهم المفاهيم الواردة، وقائمة للمراجع.

3- خطة الكتاب و أبرزما جاءت به

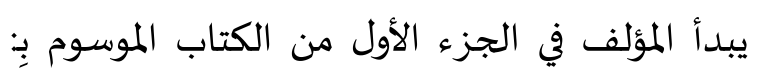
"التمويل وتطوراته الحديثة واستخدامه للرياضيات" بتحديد الإطار العام للموضوع من خلال عرض تاريخي لنظام التمويل القائم على السوق، كما جاء في الفصل الفيل

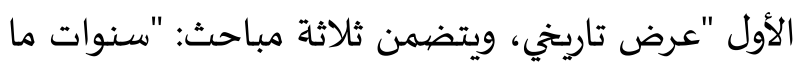

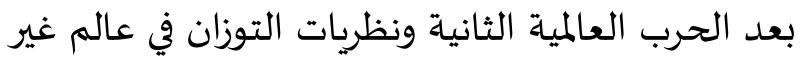
مؤكد"، و و"ثورة بلاك وسكولز"، و"مرحلة الليبرالية الجديدة"، ويليه فصل ثان عن "ماهية الرياضيات المالية" يتناول الربط الذي حدث بصفة غير متوقعة بين عالم المال والرياضيات من جراء التطورات التي جعلت الأسواق المالية بالغة التعقيد والتركيب.
ثالثا: الحساب العشوائي (stochastic calculus) لتمثيل ربح المجازفين، فإذا افترضينا أن قيمة أحد الأصيول

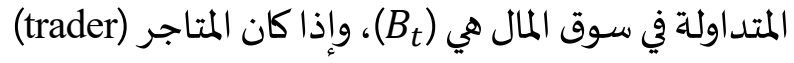
$\left(B_{1}\right)-\left(B_{0}\right)$

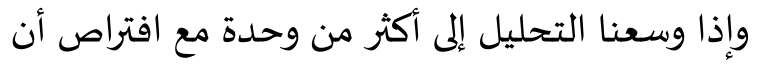

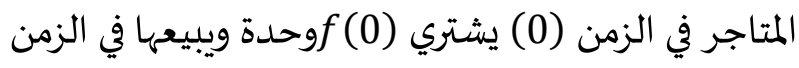

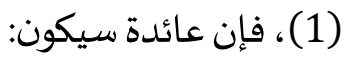
$f(0)\left(B_{1}-B_{0}\right)$

وإذا مددنا الفترة الزمنية إلى (t) بدألا من الزمن (0)، فإننا نحصل على المعادلة التالية:

$$
\sum_{n} f\left(t_{n}\right)\left(B_{t_{n+1}}-B_{t_{n}}\right)
$$

وإذا افترضنا ان التاجر يتصرف بحيث يمتلك (t) f(t) وحدة في المـدة الزمنيـة (t)، يمكـن صـيـاغة عائـده مـن خـلال التكامل (integral) بالمقارنة مع قيمة الأصل وفق ما يلي:

$$
\int_{0}^{T} f(\mathrm{t}) d B_{\mathrm{t}}
$$

وإذا ما افترضنا أن قيمة الأصل المتداول هي شكل محفظة استثمارية تتكون من (t) أصل (assets) أثناء الفترة الزمنية (0,T)، فإن عائده النهائي يصاغ في شكل تكامل عشوائي (stochastic integral) كما يلي: $\int_{0}^{T} f(\mathrm{t}) d S_{\mathrm{t}}$

هذا يبيّن أن الحساب العشوائي الذي يدرس الظواهر التي تعتمد على الزمن هو امتداد لتطبيقات نظرية الاحتمالات. وإذا كان حساب الاحتمالات بالطريقة التقليدية كما

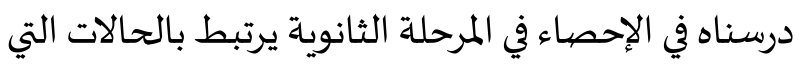
تقاس فيها أي نتيجة ممكنة بعدد محدّد، مما أفرز مفهوم التغير الاحتمالي، فإن العملية العشوائية ( stochastic 
في هذا الإطار، يُبيّن المؤلف أن الخاصية الأساسية للأسواق المالية، التي تتطابق تمامًا مع نظرية المفاضلة، هي أهها بالضرورة مضطربة من جراء المجازفة؛ فالمجازفة تولّد الاضطراب والاضطراب يجعل التعامل مع المجازفة أكثر صعوبة، وفي هذه المطاردة اللامنتهية تظل المجازفة هي الطرف الرابح للسبب الوحيد الذي يجعلها تزداد تفننًا من

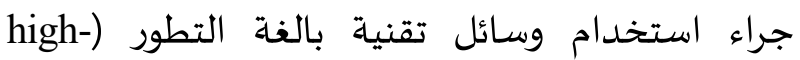
(frequency trading )، والبيانات الضخمة (big data)، والذكاء الاصطناعي (artificial intelligence)، والخوازميات القادرة على التعلم من المستخدمين (Learning algorithms) (behaviour finance)؛ "فالنظرية الرياضية للمفاضلة تصف الأسواق المالية بشكل أفضل كلما تمت ممارسة المجازفة بكفاءة أكثر " (الفصل الثامن). ما يبين أن الوسائل الفنية المتقدمة لا تستخدم في المقام الأول لتحسين حياة الناس، وإنما لخدمة مصالح الأطراف التي تستفيد أكثر من المجازفة في الأسواق المالية، وكلما تحكم المنافسون في التقنية الجديدة، كلما دفع ذلك إلى تطوير تقنية بديلة عنها.

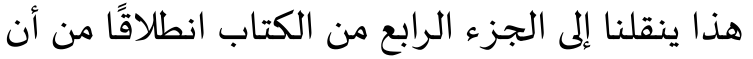

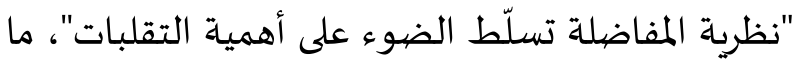
يفرض تعريف التقلبات (الفصل التاسع)، وأسبابها (الفصل العاشر)، لبيان أن التقلبات والمجازفة هما أهم خاصيتان للأسواق المالية (الفصل الحادي عشر)، هذا

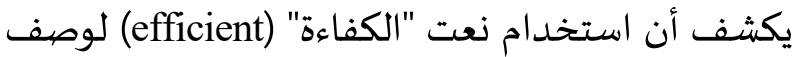
الأسواق المالية خدعة تروج إعلاميًا من غير بيّنّة (الفصل

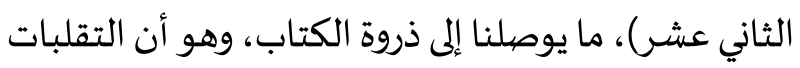
تمنع الأسواق المالية من تلبية توقعات الاقتصاديين لأنها تخفي الإشارات التي يفترض للأسعار أن تعطهيها.
ويتناول المؤلف في الجزء الثاني "الانتقادات التي وجهت للتمويل وعلميتها العالية" من خلال "الانتقادات النظرية" التي تتعلق بكيفية عمل الأسواق المالية، وهو موضوع الفصل الثالث الذي يكشف عن محاكاة العاملين في هذه الأسواق وتوجيه الرياضيات لسلوكهم، كما تناول في الفصل الرابع "الانتقادات القائمة على الواقع المعيش من التحافيات

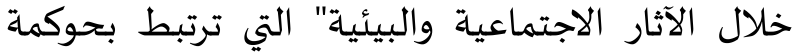
الاقتصاد من خلال الأسواق وقضايا عدم الاستقرار،

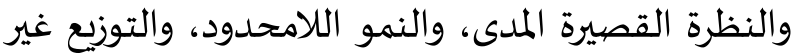
العادل للثروات والدخول، والبطالة والعلاقة الاجتماعية، وإخضاع كافة مجالات الحياة لقوانين السوق، ويأتي الفصل الخامس "الرياضيات المالية تحتل مكانة مرموقة ولكن من يفهمها حقًا؟" الذي ينقسم إلى مبحثين: "ما هي طبيعة الرياضيات التي تستخدم في المجال المالي" و"دعونا نتحدث قليلاً عن عمل المتخصصين في الرياضيات" ليبين أن جل الانتقادات تعبر عن وجهات نظر صائبة نسبيات المتيًا، ولكنها لم تفلح في تغيير المسار الذي اتخذته الأسواق

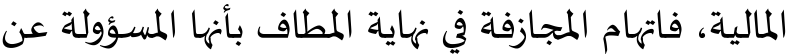

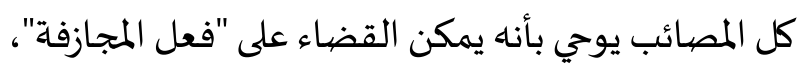
وهو ضرب من ضروب الخيال لأن المجازفة نفذت مفاصل الاقتصاد المختلفة.

ويرى المؤلف في الجزء الثالث من الكتاب "لماذا يرتكز التطبيق المالي على النظرية الرياضية" أنه من المهم بمكان تناول الموضوع بشكل مغاير، "وأمام بؤس العالم ينبغي التفكير في ما هو أبعد من منع المجازفة" (الفصل السادس)، فينبغي الانطلاق من النظرية الرياضية التي

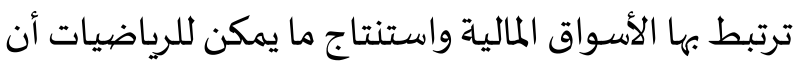
تفعله وما لا يمكن أن تقوم به. كما ينبغي استيعاب نظرية المالية

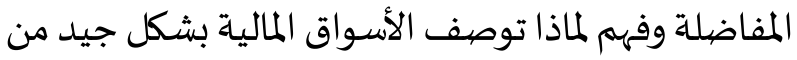
قبل هذه النظرية (الفصل السابح)؟ 
4- إنشاء الأسواق المالية يمثل خطأ تاريخيًا يرى المؤلف أنّ إنشاء الأسواق المالية بناء على نموذج كنيت أرو وجيرار دبرو (Arrow \& Debreu, 1954) وتوسيع نطاق استخدامه إلى الأسواق المالية من خلال

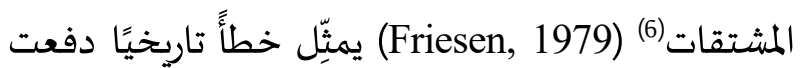

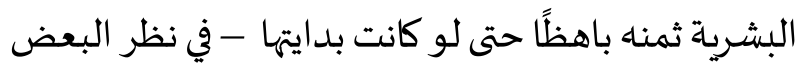

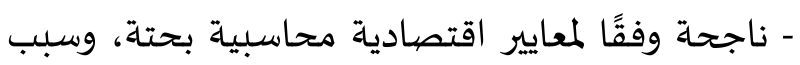

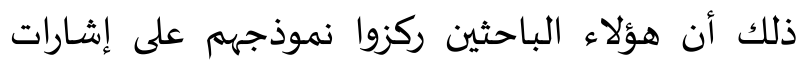

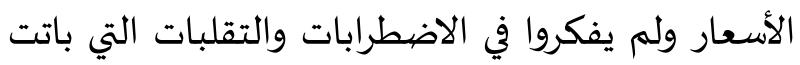

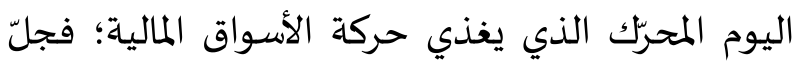
المتعاملين المتمرسين (professional traders) في الأسواق الماق المالية يستندون إلى نظرية المفاضلة. هذا الشعور يبدو بديهيًا الآن لشريحة واسعة من

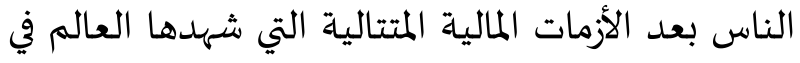
السنوات الأخيرة، وسوف تزداد القناعة بذلك في المستقبل لأن آثارها السلبية ستكون أخطر بحكم الاندماج الأكبر في الاقتصاد العالمي من جراء الانتشار السريع للتقنيات

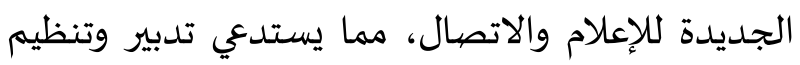
الأمور الاقتصادية بشكل مختلف، كما يتطلب تغيير مؤسسات النظام الاقتصادي؛ فمنتج التمور بالمدينة

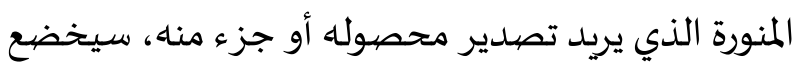

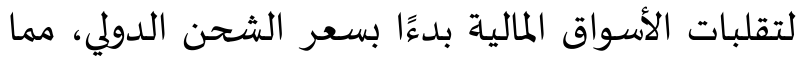
يثبط الحافز على الاستثمار في نشاط التمور مستقبلاً.

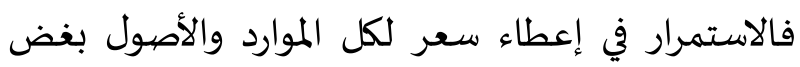
النظر عن طبيعتها وأهميتها في المحافظة على حياة البشر المراد وتحسين نوعيتها وتوطيد العلاقة الاجتماعياة، سيؤدي

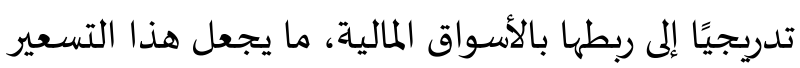

(6) لكي تقترب الأسواق المالية من هذا النموذج ينبغي أن تكون كاملة،

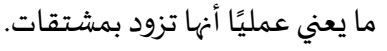

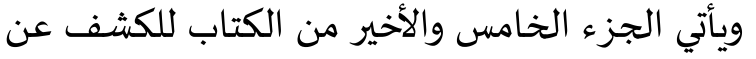

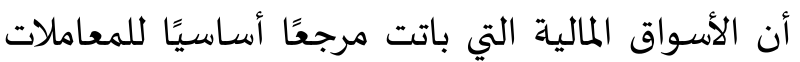

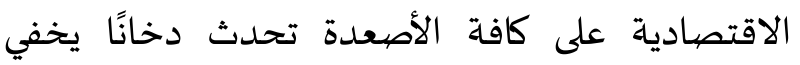
المعلومات المتوقعة ويدعم الشلل في مواجهة التحديات الكبرى التي تواجه البشرية (الفصل الثالث عشر)، ما يعني أن الأسواق المالية لا يمكنها أن تزود الاقتصاديين بما لتانيا ينتظرونه من معلومات لتحليل الوقائع وتحديد خيارات

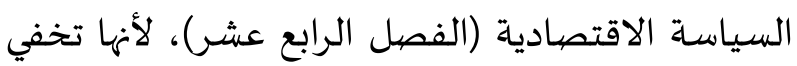

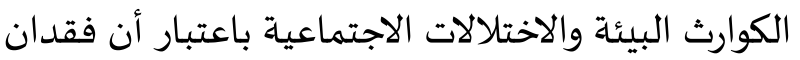

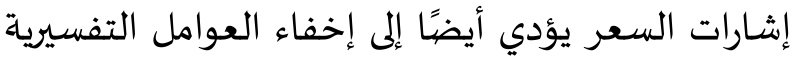
للتغييرات (الفصل الخامس عشر)، فهي أداة توجيه سيئة للغاية لأها تكرّس العمل وفقًا للمعتاد ( business as (Bouleau, 2017d) (usual هذا يتطلب توفير المعلومات بطريقة مغايرة تجعل المنشآت والمدخرين والمستهلكين يقفون على الاتجاهات العامة

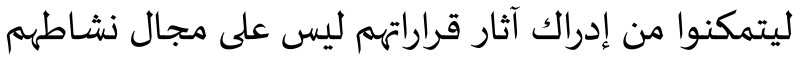
فحسي، وإنما أيضًا على حياة الناس اليومية إيجابًا وسلبًا،

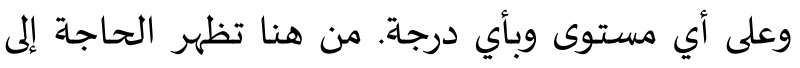
تصميم مؤشرات غير مالية تحد من التبعية لتقلبات الأسواق المالية (الفصل السابع عشر)؛ فتعاظم قوة

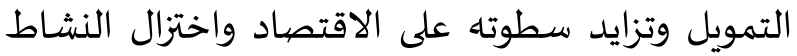

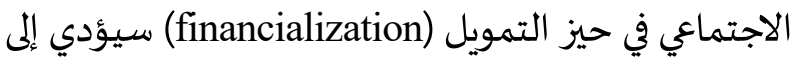

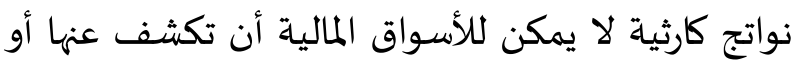
تتنبأ هها، وهي مفارقة تستحق التأمل. في الختام يدعو المؤلف إلى تعميق دراسة تاريخ التيار

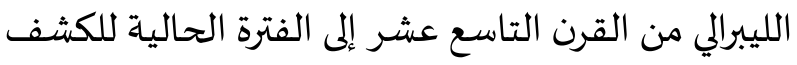
عن خلفياته واستخلاص المعرفة التي تجعلنا أكثر انتباهًا لأثر نشاط البشر على المحيط الحيوي. ومن المهم بمكان

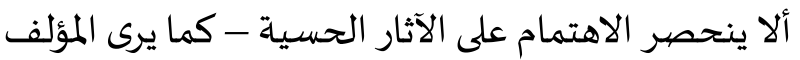

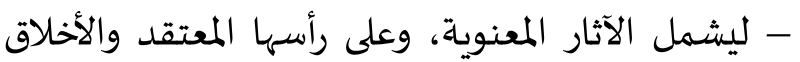

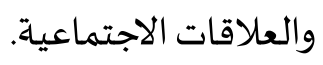


يمارس نشاطه -على غرار المهندس- من خلال لوحة معلومات تسجّل تغيرات أهم عناصر الإنتاج. وإذا كانت إدارة المنشأة ترتكز أسـاسًا على التغيرات التي تطرأ على ألى عناصر الإنتاج ، فإن أسعار هذه العناصر وتغيراتها هي أهم عامل في عملية اتخاذ القرار، وهو ما يوسم في أدبيات الاقتصاد الجزئي بإشارات الأسعار أو الإشارات السعرية (Price signals)؛ فليس هناك حاجة إلى مخططين أو إوسارل تكنوقراطيين عباقرة يديرون الاقتصياد من فوق، بل على الفاعلين الاقتصاديين أن يتتبعوا إشارات الأسعار وأن

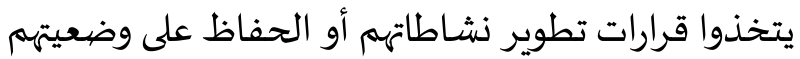
Hayek, ) التنافسية بناء على تغيرات إشـارات الأسعار

إن إمعان النظر في عنوان المقالة "استخدام المعرفة في المجتمع" يكشف لنا عن خلفيتاه الفلسفياة: هناك موجود حقيقي يغني عن غيره، وهي الأسعار واتجاهات الأسعار. ويندرج هذا التصور في سياق الفلسفة النفعية التي شهدتها الولايات المتحدة في أوائل القرن العشرين: مايهم فقط هو إمكانيات التصرف، هذا هو الواقع الحقيقي، والسعر هو الذي يحكم إمكانيات التصرف في هذه الحالة ويقودها نحو بر الأمان.

وقد أظهرت هيمنة الأسواق المالية التي فرضتها الموجة Ronald ) النيوليبرالية من جراء وصهول رونالد ريغن Reagan )، ومارغرت تاتشتر (Margaret Thatcher) إلى (فئل سدة الحكم في مطلع ثمانينات القرن العشرين أن المجازفة تخفي إشـارات الأسعار، ما يجعل تأصيل فريدريك هايك لتبرير أفضلية النظام الاقتصادي الليبرالي عما سواه غير ملائم بالنظر إلى واقع الأسواق المالية وما آل إليه وضعاه في

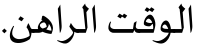

الذي بات من المسلمات ينقلب إلى دخان يخفي ما يحصل

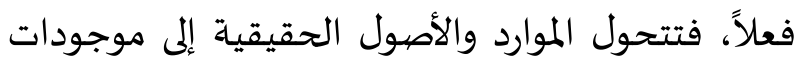

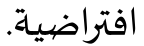

وفي هذا تحذير للذين يسعون لربط كافة النشاطات البشرية بالأسواق المالية باعتبارها ممرًا لا يمكن الاستغناء عنه للتوجياه الأمثل للموارد؛ لا سيما في مجال الأوقاف التي باتت تعدّ من مؤسسات التمويل الاجتماعي الإسلامي ومن المؤسسات المالية الإسلامية غير المصرفية، مما سيفرغها من مضمونها ويقودها بعيدًا عن غاياتها. فعدم تبني نظم

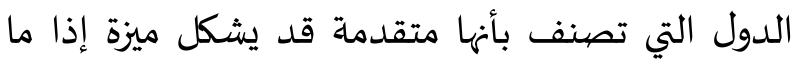
أحسن التعامل مع الموضوع بتأمل بعيدًا عن هاجس التنافسية الذي يستدعي اللحاق بالنموذج لكسب رضاه بأي طريقة وبأي ثمن حتى ولو كان هذا المتوقع مصطنعًا لا يعتد باه بالنظر إلى التشخيص الفاحص. ما يفرض اللجوء إلى مؤشرات غير مالية ترتكز على الكتلة، والحجم، والكمية، والمساحة، والنسبة على غرار تلك التي أشار إليها نادي روما في تقريره المشهور "حدود النمو" ( Meadows et

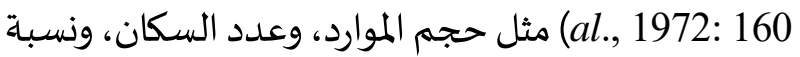
التلوث، من دون إغفال أن أهم الأشياء في الحياة لا يمكن

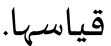

5- نقد الحجة الجوهرية التي تقوم عليها مقولة أفضلية النظام الاقتصهادي الليبرالي على غيره يرى المؤلف أن أسهل طريقة لعرض موضوع الكتاب استحضيار مقالة "استخدام المعرفة في المجتمع" التي نشرها فريدريك هايك (Friedrich Hayek) في المجلة الأمريكية للاقتصاد عام 1945م لبيان كفاءة النظام الاقتصادي الليبرالي القائم على ريادة الأعمال في السوق الحر مقارنة بالنظام الموجاه مركزيًا، فقرّر أن رجل الأعمال 
اتجاهها بسبب الغبار الرملي الكثيف الذي تحدثه؛ فيجلب

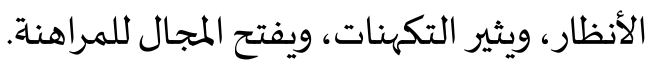
إذا أمعنا النظر في الشكل رقم (3) يتبيّن لنا أن الذي يظهر لأول وهلة ويسترعي الانتباه ليس اتجاهات إشـارات الأسعار، وإنما التقلبات التي تعمل بمثابة الغبار الرملي الكثيف، وكلّما كان حجم هذا الارتفاع والانخفاض كبيرًا كانت موجة التقلب أسرع. وهذا يعني أن تقلب سعر أصل

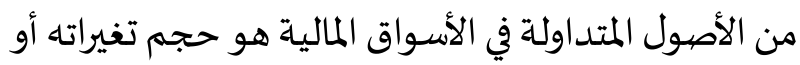

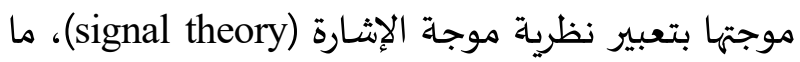
يعبر عن مدى اضطرابه وتقلبه، وهذا يعتمد بشكل كبير على الحالة المزاجية التي ينظر من خلالها العاملين في الأسواق المالية إلى هذه الأصول، ويتفاعلون من خلالها مع

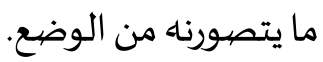

6- نقد فرضية كفاءة الأسواق المالية إذا قررت النظرية النيوكلاسيكية بناء على التعريف المشهور الذي اقترحه الاقتصادي الأمريكي أوجين فأما أنّ النّاء النئ السوق يسمى ذات كفاءة (efficient) إذا كانت الأسعار

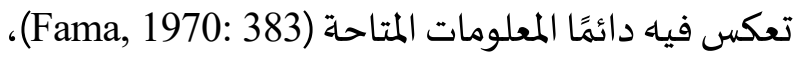
فإنّ مؤلف الكتاب يرى نقيض ذلك: إن الأسواق المالية ليست ذات كفاءة، بل هي على عكس ذلك تصدئ درّ دخانًا (fumigènes)

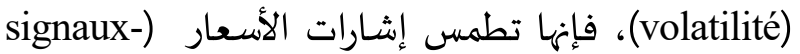
prix ، مما يمنع من اتخاذ القرارات بطريقة ملائمة. وتبيّن مما سبق أن النظرية الرياضية للمفاضلة أنّ

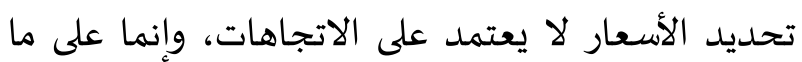
يرتبط بالتقلبات. فكأننا أمام قافلة من السيارات التي لتئي

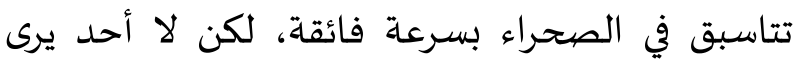

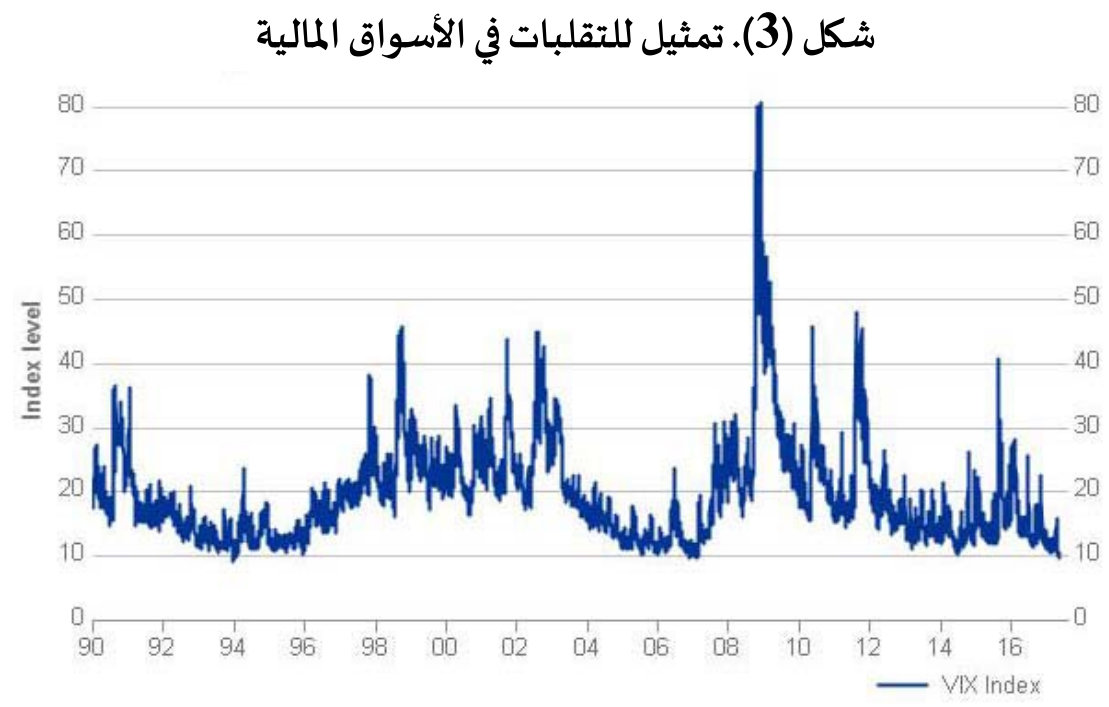

وينبغي التمييز هنا بين أشكال مختلفة للمجازفة لعل

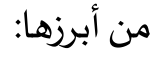
• المجازفة الاقتصادياة التي تنبع من تفسيرات للتغيرات التي تحصل في سياسات واستراتيجيات الشركات

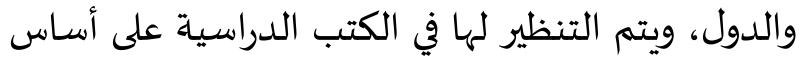
أن المجازف يأخذ على عاتقه مخاطر لا يريدها الآخرون.
ومعنى حجب التقلبات للاتجاهات أن الأسعار تتغير لكنه

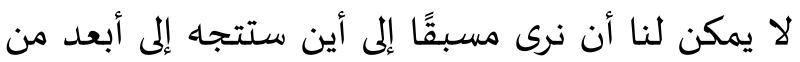
حالات الصعود والهبوط وبقاء المستويات على حالها التي تشير إليها وسائل الإعلام يوميًا؛ فنحن أمام ظاهرة غير منتظمة بطبيعتها تتقلب بشكل عشوائي. 
يراجع أفكاره ولا يتشبث برأيه. هذا يظهر أن المراجعة

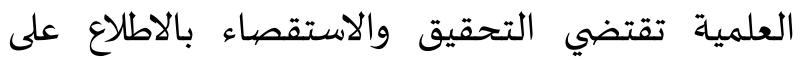
كتابات المؤلف والمقارنة بينها للوقوف على المنطلقات والخلفيات والتطورات والمراجعات التي من شأنها أن تجعل

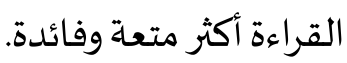

هذا التساؤل الخُلقي البالغ الأهمية لا يمكن أن يرد إلى الى التحا ذهن الرياضيين إلا من خلال القراءة الخارجية أو الحرة التي تتعدى مجال التخصص. لكن المنظومة التعليمية بشكلها الراهن تعوق تحقيق ذلك، فهي لا تعمل إلا بتوجيه الطالب نحو المعارف والتقنيات في ظروف تسعى لتعظيم فرص الحصول على وظيفة في سوق العمل، مما لا يوفر للمتعلم الوسائل لطرح تساؤلات جوهرية بشأن التناسق

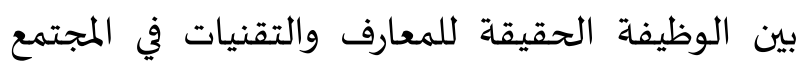
ومنظومة القيم والمثل التي يحرص عليها.

من ناحية أخرى، إن المنظومة التعليمية تميل نحو التكيف مع متطلبات السوق الذي بات من المسلمات التي

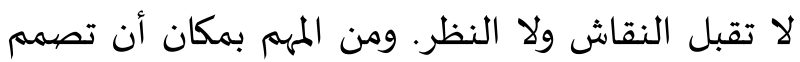
البرامج التعليمية بحيث يملك الخريج خيارات عدّة: بالإضافة إلى التكيف مع السوق، يمكن له التأثير عليه، أو

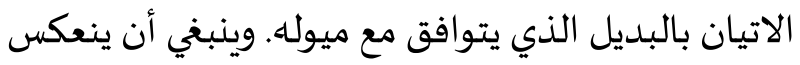

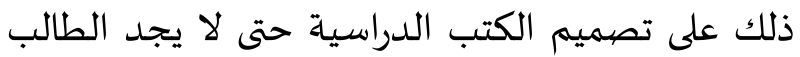
نفسه أسيرًا لنمط أحادي يكرس التبعية، فيتاح له المجال

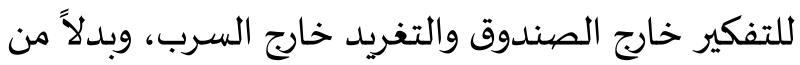
إعداده على تقبل طروحات ومسائل وقضايا جاهزة، ينبغي أن يوفر له ما يساعده على معرفة طبيعة الأرض التي يقف

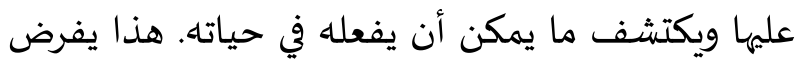
علينا أن نفكر بجدية منذ الآن في كيفية تعليم الأجيال القادمة التي سوف تواجه تحديات تشيّب العقول.
• المجازفة النفسية التي تحاول الإفادة من أن

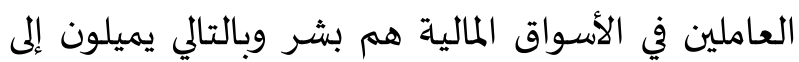
تفسير بعض الظواهر كمؤشرات، مما يدفعهم إلى اتباع توجيهات المعلقين والشائعات تماشيًا مع سلوك القطيع. • المجازفة ذات الطابع الرياضي المحض التي تمخضت عن الإفراط في استخدام الرياضيات، وهي تستفيد بشكل خاص من التحولات الاحتمالية التي لا تنتهج مسارات خطية أو من اقتراب التطبيق في الأسواق المالية شينًا فشيئًا من النظرية الرياضية كما تبيّن سابقًا. من الناحية العملية، هذه الأشكال الثلاثة ليست

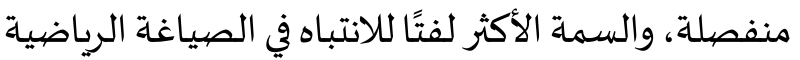

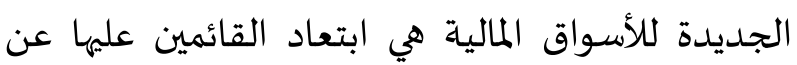

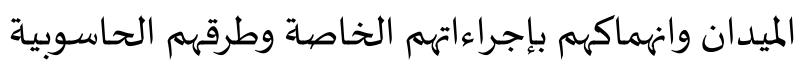

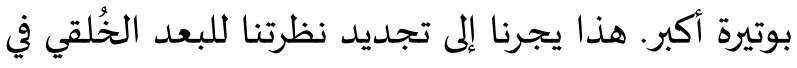
ممارسة الرياضيات إلى أبعد من النزاهة الفكرية التي يتم

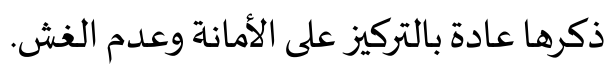

7- المسؤولية الخلقية في إخضاع الرياضيات لمصالج فئة

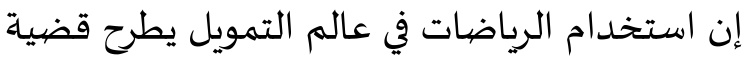
منهجية قلما يتم التنبه لها وتناولها بما تستحقاه من عمق.

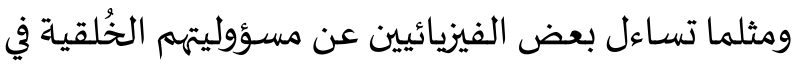
جريمة إلقاء القنابل النووية على مدينتي هيروشيما وناغازاكي، فمن المهم بمكان أن يتساءل المتخصصيين في المياء

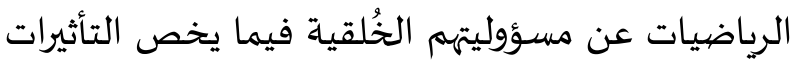
الكارثية التي تخلفها أكذوبة الأسواق المالية على الحياة المعيشية لعدد ضخم من البشر في جميع أنحاء العالم.

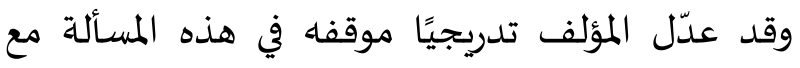

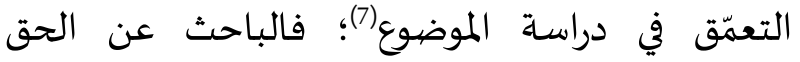

(7) أنظر على سبيل المثال المقابلة التي أجراها المؤلف مع صحيفة لوفيغرو الفرنسية منذ أكثر من عقد (7) (Bouleau, 2008). 
في الأزمات الاجتماعية، والتداعيات النفسية، والكوارث

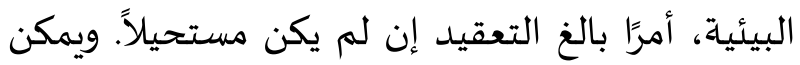
تمثيل سوق المال بالرصد الجوي الذي لا يقدر على إخبارنا

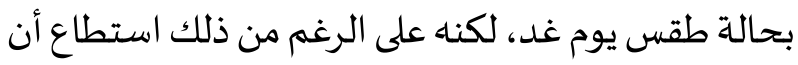
يقنعنا بشراء كل مستحضرات الوقاية من المطر ومن الحر على حد سواء، وهي من المفارقات التي لم تشد الانتباه. وحتى لا يمر الموضوع مرور الكرام، وقد يبدو سهلاً

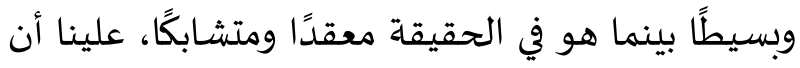
نوليه ما يستحقه من عناية واهتمام(9)، وأن نغتنم مثل هذه المراجعات العلمية لإعادة النظر في طريقة قراءتنا لنفكر بشكل مغاير بالتمييز بين ما تعلمناه من الكتب الدراسية عن النظريات الاقتصادية، وجوهر الخطاب

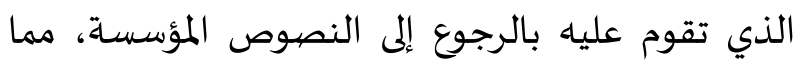
ينعكس حتمًا على تعاملنا مع منظومة بناء المعرفة برمتها، وفي مقدمتها الفروض الأساسية التي تندرج في عملية التأثير

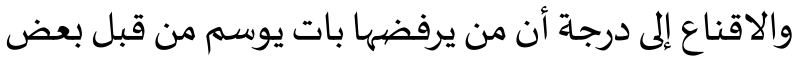
الباحثين في الاقتصاد الإسلامي. ومفاد ذلك أن الاقتصاد الإسلامي يتفق مع النظرية النيوكلاسيكية في المقولات الوصفية، وهي كثيرة، ويختلف معها قي المقولات القيمية، وهي قليلة(10.) لكن هذه الفروض التيرة ولختل ترسخت عبر عقود في الأذهان باتت محل نقد، فقد أظهر الاقتصادي توماس أنساس كوترو (Thomas Coutrot) أن الرأسمالية ليست نظامًا يسعى لتحقيق الريح قبل كل شيء، ولكنها نظام لتراكم

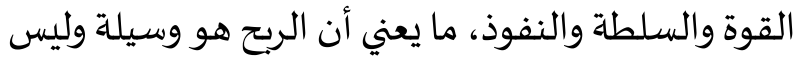

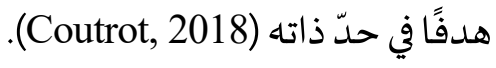

(9) لعل من المناسب في منتدى النقاش الذي تطرحه مجلة معهد الإسل

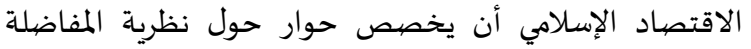
الرياضية وعلاقهها بالأسواق المالية.

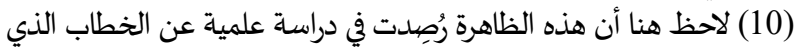

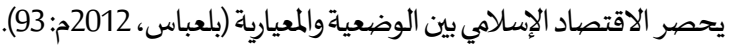

وعلى القائمين على تصميم البرامج التعليمية أن يتداركوا هذا الأمر قدر الإمكان في حدود المتاح لاسيما من خلال الحلقات الدراسية (seminars) التي تتمحور حول السؤال التالي عن دوافع استخدامنا للرياضيات: "ما هي

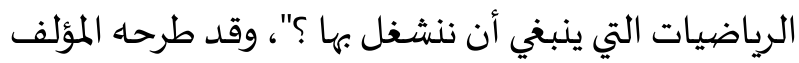
في مناسبات عدّة (Bouleau, 2017c: 17). هذا يقودنا إلى سؤالين فرعيين: من يستخدم الرياضيات؟ ولمصلحة من؟ فالرياضيات ليست أداة حيادياة، وإنما هي وسيلة تستخدم من بعض الأشخاص

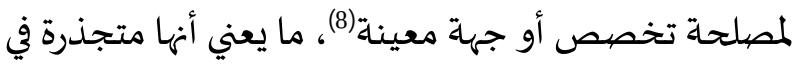
سياق محدّد وأن علاقتها تختلف بحسب اختلاف السياق،

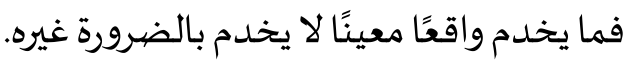

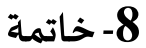
الفكرة المحورية التي نستنتجها من مراجعة الكتاب التي تتخذ شكل التحدي للنظرية النيوكلاسيكية التي تقرّر أن تغيرات الأسعار هي المعلومة الأساسية التي ترتكز عليها القرارات الاقتصادية، ما يجعل قيادة الأسواق المالية للاقتصاد من خلال الإشارات السعرية أكذوبة من غير الممكن تقبلها أو السكوت عنها، هذا يعني أن الذين يعملون الدهن في هذه الأسـواق يرون الأسعار لكنهم لا يرون اتجاهاتها التي من شأنها أن تعين على اتخاذ القرار وفق منهجية واضحة

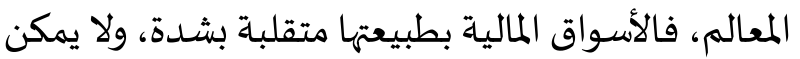
أن تتحقق المجازفة فيها من دون أن تتقلب الأسعار باستمرار، بعبارة أخرى: إن التقلب هو خاصيية ذاتية للأسواق المالية تثير دخانًا يخفي الاتجاهات الكبرى لإن

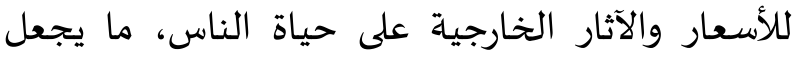
تحديد مسؤولية الأطراف الفاعلة والمستفيدة من المنظومة

(8) تظهر الدراسة التاريخية أن الرياضيات استخدمت في الماضي لحل

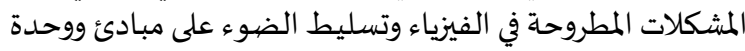

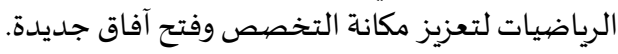


ويتضح بموجها أنّ تحديد الأسعار لا يعتمد على الاتجاهات، وإنما على ما يرتبط بالتقلبات التي تغذي نفسها من خارج ما هو محسوب اقتصاديًا، وتفرض نفسها على الجميع لأن القياسات والملاحظات والنماذج الاقتصادية تمثل أنماطًا فكرية لم ترق إلى مستوى الواقع المعات العات

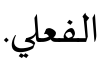

وبتضافر الجهود سنطور قدراتنا في الاستخدام الأمثل للمفاهيم حتى نصل إلى ما نصبو إليه وهو صناعة المفاهيم التي تنطلق من تساؤلاتنا، وتعبّر عن وجدانِ إننا دون نفي للآخر، وتجسّد تحررنا من ربق الكلمات الآمرة التي تملي علينا كيف ينبغي أن نفكر؛ فكل مجتمع له الحق في التعبير عن ذاته بالنظر إلى خصوصيته، ولا تتأتى هذه القدرة إلا بالتحرر من مركب النقص والهواجس التي ترسخت فينا، ما يفتح المجال إلى النظر إلى وقائعنا بعيوننا وليس بعيون

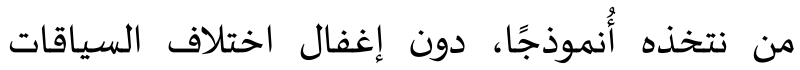

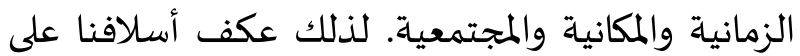
مدار قرون فيما يخص حياتهم المعيشية على استخدام مفاهيم مختلفة لعل من أبرزها: الخراج، والأموال،

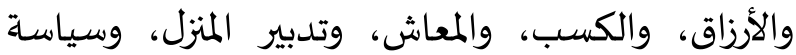
المدينة، وأوجه معاش العمران البشري أو الاجتماع والداع المان

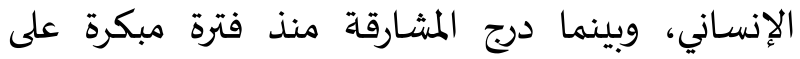
استخدام مفهوم الوقف، شاع بين المغاربة مفهوم الأحباس؛ والأمثلة من هذا النوع أكثر من أن تحصر. هذا التنوع في التعبير يعكس أصالة وتجذر في الواقع المعيش، التئه كل بحسب بيئته وأعرافه وعاداته وتقاليده ووسطه المحلي بعيدًا عن التبعية الثقافية سواء كان محورها داخلي أو خارجي، فالتنوع الثقافي يشحذ الأذهان، ويثير التفكير، ويبعث على التأمل، ويقوي التواصل، ويثري المعرفة.
كما علينا أن نتعامل بجدية مع ظاهرة "تريض" (mathematisation) والنظرة الاختزالية والسيطرة على العقول على حساب الإبداع الحر والتنويع لطرق فهم الوقائع والظواهر والسلوكيات، وقد نبه عليها إلى حدّ بعيد عبد الواحد يحي - روني غينون قبل إسلامه - منذ أكثر من سبعة عقود في كتابه "عهد الكم وعلامات الساعة" الذي نشر بالفرنسية (Guénon, 1945) وترجم إلى الإنجليزية (Guénon, 1953). فيما يخص المفاهيم الأساسية، فإن أبرز ما يمكن استخلاصه من خلال المقارنة الدقيقة بين ما يطبق في الماني الأسواق المالية ونظرية المفاضلة في الرياضيات ما يلي: • المجازفة (speculation) هي حرية الشراء والبيع الفوري لما هو مدرج في الأسواق المالية حسب الكمية المرادة. • م المفاضلة (arbitrage) هي الإفادة من فارق الأسعار في الأسواق لتحقيق أرباح سريعة. • التقلب (volatility) هو التذبذب والاهتزاز والاضطراب غير المرتب لقيمة المتداول في الأسواق المالية. هذا يستدعي التمييز الدقيق بين المجازفة والمفاضلة الذي خفي حتى الآن على جلّ الاقتصاديين والمتخصصين في التمويل بشكل أخص مع مراعاة أشكال متعددة للمجازفة، وهي المجازفة الاقتصادية، والمجازفة النفسية، والمجازفة ذات الطابع الرياضي المحض، وهذه الأشكال الثلاثة ليست منفصلة من الناحية العملية. والمسألة الجوهرية في هذا المقام، ما تكشف عنه النظرية الرياضية للمفاضلة من ناحية التحليل، فهي تُجزئ سعر الأصول المدرجاة في الأسواق المالية إلى جزئين: ما يرتبط بالقمار ويتغير بطريقة متقطعة، وما يسمح بقياس اتجاه أكثر انتظامًا على مدار فترة زمنية محددة. 


\section{المراجع}

$$
\text { أولاً: المراجع العربية }
$$

بلعباس، عبدالرزاق (2011م). الندرة والمصلحة الخاصية والتعظيم من الزاوية الإسلامياة: مناقشة منهجية لمحاضرة

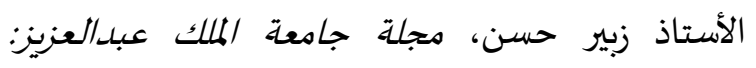

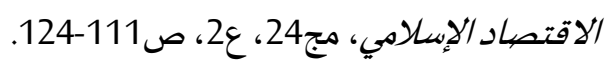

بلعباس، عبدالرزاق (2012م). الاقتصاد الإسلامي إلى ما وراء

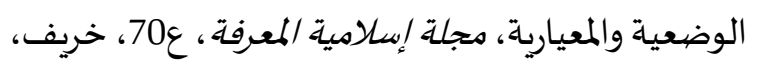

$$
\text { ص97-67. }
$$

دولوز جيل وغتاري فليكس (1997م). ما هي الفلسفة؟، ترجمة ومراجعة وتقديم: مطاع صفدي، وغئري فيروت: المركز

$$
\text { الثقافي العربي ومركز الإنماء القومي. }
$$

إن تسجيل معاملاتنا اجتماعيًا وفقًا لهذا النمط المعيشي المتجذر في عمق التاريخ الإنساني يفرض علينا

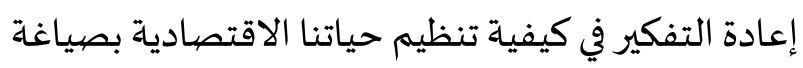
قواعد سلوكية نستعيد من خلالها تدريجيًا ثقافة امتداد النشاط البشري في الزمن (11) حسب القدرة والحاجة بحيث

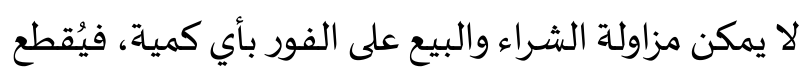
دابر المجازفة على خلاف ما قرره المؤلف في مناسبات عدّة من أن المجازفة سلوك حر يمتد إلى كل مجالات الحيات الحياة

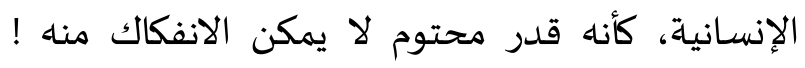
فالحرية على امتداد التاريخ البشري لم تكن مطلقة، وإنما

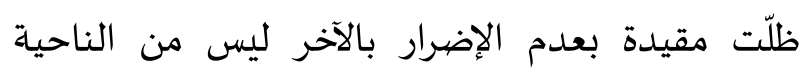

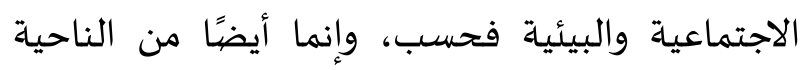
الروحية والنفسية والعقلية والخلقية.

(11) هذا يفرض عدم اختزال زمن حياة البشر في زمن الأسواق المالية،

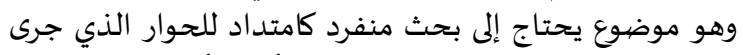
بين هنري برغسون (Henri Bergson) وألبرت أنشتاين (Elbert (Einstein 
Académie française (1835). Dictionnaire de l'Académie Française, $6^{\mathrm{e}}$ édition, Paris : Imprimerie et Librairie Firmin Didot Frères, Imprimerie de l'Institut de France.

Arrow, Kenneth J. and Debreu, Gérard (1954). Existence of an equilibrium for a competitive economy, Econometrica, Vol. 22, No. 3, pp. 265-290.

Black Fischer and Scholes, Myron (1973). The pricing and corporate liabilities, Journal of Economy, Vol. 81, No. 3, May, pp. 637-659.

Bouleau, Nicolas (1998). Martingales et marchés financiers, Paris : Odile Jacob.

Bouleau, Nicolas (2008). «Les mathématiciens financiers ne sont pas dans le projet Manhattan en train de fabriquer la bombe d'Hiroshima», propos recueillis par Yves Miserey, Le Figaro, 29 octobre.

Bouleau, Nicolas (2009a). Malaise dans la finance, malaise dans la mathématisation, Esprit, février, pp.37-50.

Bouleau, Nicolas (2009b). Mathématiques et Risques financiers, Paris: Odile Jacob.

Bouleau, Nicolas (2011). On Excessive Mathematization, Symptoms, Diagnosis and Philosophical bases for Real World Knowledge, Real World Economics, 57, pp.90105.

Bouleau, Nicolas (2013a). L'excessive mathématisation. Symptômes et enjeux, in $\mathrm{Du}$ risque à la menace: Penser la catastrophe, sous la direction de Dominique Bourg et Pierre-Benoît Joly et Alain Kaufmann, Paris: Presses Universitaire de France, pp. 77-108.

Bouleau, Nicolas (2013b Teeth of the Market, How Neoliberal Economy Obscures Information about the State of the Planet, Kindle edition.

Bouleau, Nicolas (2017a). La science comme ce qui est à transmettre, La Jaune et la Rouge [revue mensuelle de la société amicale des anciens élèves de l'Ecole Polytechnique], No. 722, pp. 24-27.

Bouleau, Nicolas (2017b). Wall Street ne connaît pas la tribu borélienne et autres essais aux frontières de la pensée stochastique, Paris: Spartacus IDH.

Bouleau, Nicolas (2017c). Introduction à la philosophie des sciences, Paris: Spartacus-IDH, https://spartacusidh.com/liseuse/BE/

Bouleau, Nicolas (2017d). Finance et "Business as usual”, Institut Louis Bachelier, Chaire Energie et Prosperite, https://www.louisbachelier.org/wpcontent/uploads/2017/09/ilb_ chaire_energie _06_17web.pdf

\section{ثانيًا: المراجع الأجنبية}

Bouleau, Nicolas (2018). Le mensonge de la finance: Les mathématiques, le signal-prix et la planète, Paris : Editions de l'Atelier.

Bouleau, Nicolas (n.d.). Adieu la finance, http://www.nicolasbouleau.eu/finance/adieu-la-finance/

Bouleau, Nicolas, Curriculum Vitae, http://cermics.enpc.fr/ bouleaun/

Coutrot, Thomas (2018). « L'organisation capitaliste du travail privilégie le pouvoir au profit », Alternatives Economiques, propos recueillis par Catherine André, 12 juin.

Deleuze, Gilles (1975). Sur la language, cours extrait d'un cours prononcé à l'Université de Vincennes, https://www.youtube.com/watch?v=Wfwh3aX4_1o

Fama, Eugene (1970). Efficient Capital Markets: A Review of Theory and Empirical Work, Journal of Finance, Vol. 25, No. 2, May, pp. 383-417.

Friesen, Peter H. (1979). The Arrow-Debreu Model Extended to Financial Markets, Econometrica, Vol. 47, No. 3, pp. 689-707.

Guénon, René (1945). Le Règne de la Quantité et les Signes des Temps. Paris: Éditions Gallimard.

Guénon, René (1953). The Reign of Quantity and the Signs of the Times, translated by Lord Northbourne, London: Luzac \& Co,

Habermas, Jürgen ([1968]1973). La technique et la science comme idéologie, Paris : Gallimard.

Hayek, Friedrich A. (1945). The Use of Knowledge in Society, American Economic Review; Vol. XXXV, No. 4, pp. 519-530.

Klamer, Arjo (1984). Conversations with Economists, Totowa, New Jersey: Rowman \& Allanhead.

Kuhn, Thomas ([1977]1990). La tension essentielle, Paris : Gallimard.

Lakatos, Imre ([1978]1994). Histoire et méthodologie des sciences: Programmes de recherche et reconstruction rationnelle, Paris: Presses Universitaires de France.

Latour, Bruno and Wooglare, Steve ([1979] 1996). La Vie de laboratoire. La production des faits scientifiques, Paris: La Découverte, collection Poche.

Latour, Bruno (1991). Nous n'avons jamais été modernes. Essai d'anthropologie symétrique, Paris, La Découverte.

Meadows, Dennis, Meadows, Donella, Randers, Jørgen and Behrens III, William W. (1972). The Limits to Growth, New York: Universe Books. 
Modigliani, Franco and Miller, Merton H. (1958). The cost of capital, corporation finance and the theory of Investment, The American Economic Review, Vol. 48, No. 3, June, pp. 261-297.

Modigliani, Franco and Miller, Merton H. (1961). Dividend Policy, Growth, and the Valuation of Shares, The Journal of Business, Vol. 34, No. 4, October, pp. 411-433.

Segerstrale, Ullica (2000). Beyond Science Wars: The Missing Discourse about Science and Society, New York: State University of New York Press.

Stengers, Isabelle (1997). Cosmopolitiques, tome 1: La Guerre des sciences, Paris: La Découverte.

\section{Translation of Arabic References}

Belabes, Abderrazak (2011). Scarcity, Self-interest and Maximization from Islamic Angle A Methodological Discussion of Zubair Hasan's Paper, Journal of King Abdulaziz University: Islamic Economics., July, Vol. 24(2), pp. 109-122.
Stengers, Isabelle (2013). L'invention des sciences modernes, Paris: Flammarion.

Stengers, Isabelle (2013). Une autre science est possible! Manifeste pour ralentissement des sciences, Paris: Les Empêcheurs de penser en rond.

Tirole, Jean (2015). Lettre de Jean Tirole à Najat VallaudBelkacem, http://assoeconomiepolitique.org/wpcontent/uploads/Lettre-de-jean-Tirole.pdf

Whitehead, Alfred North ([1929]1995). Procès et réalité: Essai de cosmologie, Paris: Gallimard, Collection Bibliothèque de Philosophie.

Belabes, Abderrazak (2012). Islamic Economics beyond the 'Positive/Normative' Dichotomy, Islamiyat alMa'arifa, Vol.18, No.70, pp. 67-96.

Deleuze, Gilles and Gattari, Félix (1997). What is Philosophy?, Beirut: al-Markaz al-Thaqāfī al-Arabī and Markaz al-Inmā' al-Qawmī. 
عبدالرزاق سعيد بلعباس: باحث بمعهد الاقتصاد الإسلامي، جامعة الملك عبدالعزيز، جدّة؛ حاصل على شهادة مهندس في الإلكترونيك، وماجستير في القياس الاقتصادي، ودكتوراه في التحليل والسياسة

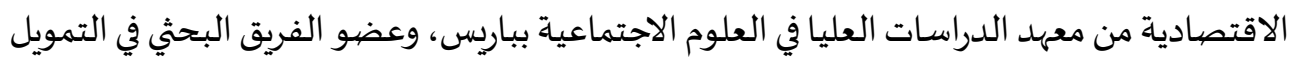
الإسلامي بجامعة ستراسبورغ الفرنسية. من أبحاثه الحديثة المنشورة في مجلات علمياة محكيمّة: "التفاعل بين التمويل وعلوم الخلايا العصبية من منظور إسلامي إلى أبعد من الدماغي" (2015م)؛

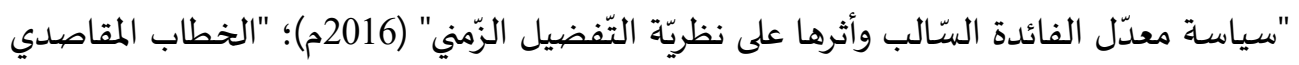

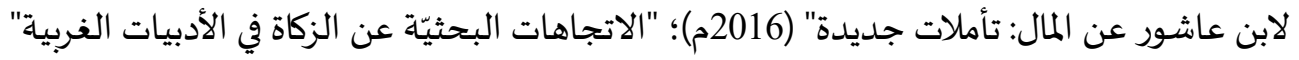

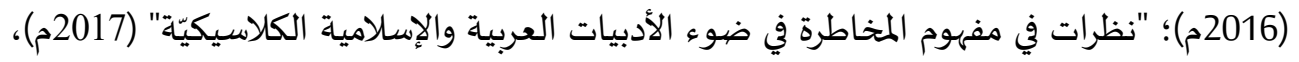
"هل الوقف جزء من القطاع الثالث؟" (2017م)، "نشأة مصطلح الاقتصاد السياسي في العالم الإسلامي: دراسة مقارنة بين الأدبيات العربية والتركية والأردية" (2017م). البريد الإلكتروني: abelabes@kau.edu.sa 


\title{
The Lie of Financial Markets: Mathematics, Price Signal and the Planet By: Nicolas Bouleau
}

\author{
Reviewed by: Abderrazak Said Belabes \\ Associate Professor \\ Researcher, Islamic Economics Institute \\ King Abdulaziz University, Jeddah, Saudi Arabia
}

\begin{abstract}
The book raises a fundamental question about the reality of price signal in the global financial markets on which the neoclassical discourse is based: Can it be considered as basic information in the analysis of facts and the formulation of economic policies to limit the unequal distribution of incomes and damage to the environment? The book shows that directing economy through price signal is just a lie. Volatility is an intrinsic characteristic of financial markets that generate a smoke and hides major price trends and externalities which negatively affect people's lives. The book explains how the application of advanced mathematical theories has enhanced the ability to master the advantage of price differentials. The more the degree of sophistication increases, the more the application approximates theory. The mathematical modelling used in the financial world is not just a description of what happens, it is performative. This raises an ethical question that is rarely noticed: What mathematics should we be preoccupied with? For whose benefit?
\end{abstract}

Keywords: financial markets, volatility, risk, arbitrage pricing theory, performativity.

JEL Classification: B26, C02, D53, G14

KAUJIE Classification: F51, H24 